\title{
Aplicação do conceito de Unidade Morfo-territorial na escalas metropolitana, intraurbana e local
}

\author{
Jonathas M. P. Silva, Fernanda Lima e Natalia C. T. Magalhães \\ PUC-Campinas - Pontifícia Universidade de Campinas - PosUrb - Pós-graduação em \\ Urbanismo; Rodovia Dom Pedro I, Km 136 - Parque das Universidades, Campinas - SP, \\ 13086-900, Brasil. E-mails: jonathas.silva@ puc-campinas.edu.br, \\ fernandalima.fcl@gmail.com, nataliacristina.tripoli@gmail.com
}

Artigo revisto recebido a 17 de Setembro de 2015

\begin{abstract}
Resumo. A forma urbana contemporânea observada na Região Metropolitana de Campinas, resultante do processo de dispersão e fragmentação, necessita ser melhor estudada. O presente artigo apresenta métodos de análise provenientes de diferentes áreas: morfologia, ecologia e estudos da paisagem urbana. Os conceitos, métodos e procedimentos aqui apresentados tiveram a contribuição da rede de pesquisadores chamada QUAPÁ-SEL (Quadro do Paisagismo - Sistema de Espaços Livres) que estuda a relação entre o sistema de espaços livres e a forma urbana. Adota-se uma abordagem de análise em três diferentes escalas: i) região metropolitana, formada por 20 municípios; ii) bairros, constituídos de diferentes tecidos urbanos; e iii) quadra urbana, onde o espaço edificado e o espaço livre de edificação geram o espaço urbano. Nas três escalas o sistema de espaços livres é o protagonista da análise. $O$ resultado apresentado indica os ganhos que os procedimentos de leitura e análise oferecem na compreensão do processo de fragmentação e dispersão urbana. O método adotado busca aproximar técnicas de análise de diferentes campos do conhecimento integrando os procedimentos adotados nos estudos morfológicos às técnicas utilizadas no campo da ecologia e nos estudos sobre a paisagem urbana.
\end{abstract}

Palavras-chave: morfologia urbana, forma urbana, paisagem, ecologia

O presente artigo é produto do esforço coletivo da rede QUAPA-SEL criada em 1993 que é coordenada por Sílvio Soares Macedo (FAUUSP) envolvendo diversas universidades em diferentes estados brasileiros. No estado de São Paulo a PUCCampinas, Pontifícia Universidade Católica, por meio do PosUrb - pós-graduação em urbanismo e a USP, Universidade de São Paulo, por meio de suas duas unidades: a Faculdade de Arquitetura e Urbanismo de São Paulo (FAUUSP) e o Instituto de Arquitetura e Urbanismo de São Carlos (IAU) participam de um projeto de pesquisa comum.

Nos últimos anos a referida rede de pesquisa QUAPA-SEL procura estabelecer a relação entre a forma urbana e o sistema de espaços livres de edificação considerando a presença ou ausência de políticas de solo urbano. Acredita-se que o valor da terra estabelece padrões de ocupação que irão induzir paisagens urbanas com diferentes características. É por conta do valor do solo que a população acaba assumindo um maior ou menor deslocamento. É também no solo, onde se concretizam os diferentes interesses na expansão da malha urbana. Procura-se portanto incorporar o valor do solo urbano na análise da forma urbana.

Cabe ressaltar que a nova constituição brasileira introduziu o conceito da 'função social da propriedade' que, lograria ser implementado, por meio de instrumentos urbanísticos de regularização do solo e de recuperação de mais valia do solo urbano. 
Estes instrumentos foram regulamentados pela lei federal 10.257 de 2001, que ficou conhecida como Estatuto da Cidade. Entretanto depois de 14 anos de sua aprovação poucos efeitos tiveram estes instrumentos no sentido de implantar a função social do solo urbano. Desta forma, o livre mercado irá tratar o solo como mercadoria sem haver um controle que faça prevalecer o interesse público. Mapear o processo de valorização do solo urbano pode indicar relações constitutivas da forma das cidades estudadas.

Parte-se de bases teóricas longamente construídas e lentamente consolidadas nas áreas de arquitetura e urbanismo. Desta forma podem-se lançar algumas premissas e pressupostos de análise. Primeiro, a crença de que a análise ou intervenção em uma determinada escala não prescinde do conhecimento das demais escalas. Apegados a essa visão de mundo, procurou-se, no desenvolvimento da pesquisa, desenvolver um método de análise que lidasse com diferentes escalas do território (Conzen, 1988; Lamas, 1993; Whitehand, 2007). Segundo, entende-se que o estudo da forma urbana não está descontextualizado das contradições sociais que a produziram (Costa, 2007; Conzen, 1988; Lamas, 1993; Whitehand, 2001).

A novidade está na aplicação de métodos de análise, desenvolvidos pelo conhecimento acumulado na morfologia urbana, considerando as pesquisas feitas por Nestor Goulart Reis, que identificam um modelo específico de ocupação territorial denominado por dispersão urbana (Reis, 2006). 'Dispersão urbana pode ser caracterizada: i) pelo esgarçamento do tecido urbano dos principais centros; ii) pela formação de constelações ou nebulosas de núcleos urbanos de diferentes dimensões, integrados em uma área metropolitana ou em um conjunto ou sistema de áreas metropolitanas; iii) pela transformação do sistema de vias de transporte inter-regionais (ferroviários e rodoviários) em apoio ao transporte diário intra-metropolitano de passageiros; e iv) pela adoção de modos metropolitanos de consumo, também eles dispersos pela área metropolitana ou sistema de áreas metropolitanas, como já ocorre em São Paulo (Reis, 2006, p. 13).
$\mathrm{O}$ presente artigo apresenta os procedimentos de análise aplicados a três diferentes escalas, que denominamos aqui de metropolitana, intraurbana e local (quadra urbana). Salienta-se que os termos que se utilizam para denominar as três escalas são utilizados, no presente texto, com a única finalidade de facilitar a denominação dos recortes em análise. Portanto não são termos universais nem se quer definir ou limitar, a três, o número de escalas a serem compreendidas. Acredita-se que as escalas de abordagem variam conforme o contexto, $\mathrm{o}$ objetivo da análise $\mathrm{e}$, porque não, a disponibilidade de informações.

Os recortes territoriais estudados são: i) Regional: Região Metropolitana de Campinas (RMC) de aproximadamente $3920 \mathrm{~km}^{2}$, formada por 20 municípios, localizada na região sudeste do Brasil; ii) Intraurbana: Subbacia Hidrográfica do Ribeirão das Anhumas; recorte em área consolidada da cidade de Campinas, núcleo da RMC, dotada de infraestrutura e localizada na porção territorial com valor do solo mais elevado do município; iii) Local: escala da quadra urbana, identificando tipos morfológicos e relacionando-os com as demais escalas.

O Brasil é composto por três entes federativos: federação, estados e municípios. As regiões metropolitanas não se constituem em entes federativos. As regiões metropolitanas surgiram sob um regime totalitário pela Lei Complementar n. ${ }^{\circ} 14$ de 1973, que seriam integradas à política urbana nacional. Com a Constituição de 1988 a decisão de constituição de regiões metropolitanas passa a ser atribuição dos governos de estado, entretanto, não houve até o momento, nenhum estado que regulamentou a dotação orçamentária para as regiões metropolitanas enfraquecendo, na prática, uma ação integrada de planejamento.

Adota-se a morfologia como estudo das formas e dos fenômenos que lhes deram origem (Lamas, 1993). Conforme nos lembra Stael Pereira Costa no artigo 'O estudo da forma urbana no Brasil': 'Os primeiros estudos sobre o tema estão relacionados aos aspectos econômicos, sociais e políticos das formas urbanas brasileiras, empreendidos por historiadores, como Sérgio Buarque de Holanda, e sociólogos, como Gilberto Freire na $1^{\text {a }}$ metade do século XX' (Costa, 2007). 
Nos campos disciplinares da arquitetura e urbanismo, o estudo da forma urbana possibilita estabelecer as relações entre as demandas sociais (por moradia, transporte, saúde, ensino, alimentação, lazer, etc.) e os espaços urbanos e rurais resultantes desta disputa.

$\mathrm{O}$ presente texto apresenta alguns procedimentos, utilizados em diferentes escalas, que tem como finalidade a análise da relação existente entre o sistema de espaços livres e a forma construída. Toma-se o valor do solo como um dos fatores que irão imprimir características no espaço construído e no espaço livre de edificação.

A leitura da paisagem (Macedo, 1997), por meio do método de delimitação de áreas homogêneas contribui para o entendimento da forma urbana instigando a verificação das contradições existentes e dos produtos espaciais resultantes das disputas sociais. Chamam-se estas áreas de Unidades Morfoterritoriais, cunhando assim um termo novo. Poder-se-ia adotar o termo unidade de paisagem, entretanto este possui diferentes conceituações dependendo do campo teórico, como se verá a seguir.

O termo parte da percepção que a definição de uma região onde a paisagem se mostra homogênea se apoia nas suas características morfológicas e, simultaneamente, na constituição de territórios formados pela ação de grupos sociais sobre um determinado suporte físico. A identificação das características, entraves e oportunidades de uma determinada Unidade Morfo-territorial orienta as ações de planejamento de forma a considerar as particularidades espaciais existentes.

$\mathrm{O}$ conceito de unidade de paisagem surge no campo da geografia e é incorporado fortemente pelo campo de investigação da Ecologia da Paisagem, ciência que sempre considera a presença do homem, mas que nem sempre tem como foco sua inclusão no território. No estabelecimento das unidades de paisagem, quando trabalhadas por ecólogos ou geógrafos, não se costuma considerar os diferentes matizes urbanos. Normalmente utliza-se a tradicional listagem de 'coberturas' que adota como homogênea todas as áreas urbanas sem considerar suas diferentes formas e dinâmicas.

Para explicitar a abordagem geográfica, na constituição do campo disciplinar da ecologia, Jean Paul Metzger, explicita o uso e o conceito das unidades de paisagem pela geografia: 'Três pontos fundamentais caracterizam essa abordagem geográfica: a preocupação com o planejamento da ocupação territorial, através do conhecimento dos limites e das potencialidades de uso econômico de cada unidade da paisagem (definida, nessa abordagem, como um espaço de terreno com características comuns); o estudo de paisagens fundamentalmente modificadas pelo homem, as paisagens culturais (Tricart, 1979), que predominam no espaço europeu; e a análise de amplas áreas espaciais, sendo a ecologia de paisagens diferenciada, nessa abordagem, por enfocar questões em macro-escalas, tanto espaciais quanto temporais (sendo assim uma macroecologia)' (Metzger, 2001, p. 3).

A ciência avança por meio do questionamento e construção de 'conceitos' que por sua vez, para serem bem entendidos e assimilados, necessitam de 'termos' que passam a denominá-lo com clareza. (Santos, 2002). Enquanto não fica claro os conceitos e objetivos dos novos termos criados não é possível estabelecer um diálogo profícuo entre pesquisadores, quer sejam eles de uma mesma área, quer tenham origens em campos distintos da ciência. Quando os conceitos se mostram imprecisos, os termos a eles relacionados são fadados ao pré-conceito gerando a perda de oportunidade de construção do conhecimento. Segundo Mikhail Bakhtin, pensador sócio-histórico, que valorizava a interação social no ensino, o conhecimento só pode se desenvolver com a percepção dos preconceitos de cada um. É a partir desse ponto de vista que se revela o processo criativo no qual a descoberta é promovida pelo confronto de diferentes visões. Portanto, não há criação sem contestação (Bakhtin, 1997).

Se Bakhtin tem como objeto de estudo a filosofia da linguagem, os arquitetos e urbanistas tem como interesse as formas de uso, ocupação e apropriação de territórios urbanos e rurais, onde a sociedade constrói e transforma a paisagem. Estabelecendo-se um paralelo transdisciplinar tome-se a afirmação de Bakhtin ao tratar da questão da poética clássica e neo-clássica, onde aponta que: 'Conteúdo e forma devem ser igualmente 
adequados um para o outro. A seleção do conteúdo e a seleção da forma constituem um e o mesmo ato estabelecendo a posição básica do criador; e nesse ato uma e a mesma avaliação social encontra expressão' (Bakhtin, 1976, p. 18).

Certamente nossos objetos de investigação são bastante distintos, entretanto, tanto poesia como paisagem são resultantes de fatos sociais onde, para um determinado conteúdo, tem-se a manifestação de sua forma. Enquanto a primeira trata da interação entre sociedade e linguagem, a segunda lida com as contradições entre sociedade e território.

As áreas da arquitetura e urbanismo incorporaram os conceitos conferindo a eles um novo olhar. Quando as áreas homogêneas de paisagem são tratadas nos campos da arquitetura e urbanismo consideram-se aspectos que permitem a melhor compreensão dos espaços e da paisagem urbana. Para exemplificar alguns dos aspectos mais específicos do urbano pode-se citar: i) a forma do parcelamento (ex.: constituição das vias, quadras, espaços de lazer, espaços institucionais, áreas de preservação e proteção ambiental); ii) os tipos de usos e ocupações (ex.: padrão edilício, afastamentos, recuos, tamanho de lote, etc.); iii) as tendências ou constatações de transformação (ex.: potencial edilício permitido pela legislação; processo de verticalização, desmembramentos, remembramento; alteração de uso; etc.); iv) os espaços livres de edificação (ex.: padrão viário, das calçadas, dos cercamentos dos lotes; dimensões e articulações das praças e parques urbanos); v) a renda e valor de solo da população moradora; e, por fim, vi) a mobilidade do território explicitado pelas pesquisas de origem e destino da população.

A listagem acima não tem a intenção de esgotar o tema, mas sim exemplificar aspectos físicos e socioeconômicos que são próprios do entendimento dos espaços urbanos. Portanto existem outros itens como, por exemplo, a topografia, o sistema hídrico que também podem ser parâmetro, na delimitação das áreas homogêneas, denominadas aqui de Unidades Morfoterritoriais, conforme seja sua relevância e conveniência para o estudo.

Quando se investigam diferentes métodos e instrumentos de gestão, as diferentes disciplinas que trabalham com a realidade urbana lidam com conceitos que podem sugerir uma sobreposição ou conflito de abordagens. Este é o caso das: i) 'unidades de gestão' (utilizadas na elaboração de políticas públicas, ex.: Lei Nacional de Saneamento Básico); ii) 'unidades de planejamento' (utilizadas por diversas prefeituras, ex.: Belo Horizonte, Rio de Janeiro); e iii) 'unidades climáticas' (utilizadas pelos que atuam na área de clima urbano, ex.: Pezzuto, 2007).

As diferentes abordagens, acima citadas, estabelecem recortes territoriais e têm em comum o único fato de que cada uma delimita, sobre o território, suas unidades. Por terem objetivos distintos não resultam, obrigatoriamente, em limites coincidentes. Entretanto, o fato dos limites não serem os mesmos, não gera necessariamente conflitos entre as abordagens. Cada abordagem tem seu objetivo e desenvolve o trabalho a partir de visões complementares, que podem revelar as questões contraditórias, assim como, indicar entraves e oportunidades frente a uma política pública ou a gestão territorial. Da mesma forma, as unidades de paisagem carregam uma leitura específica que revela a forma urbana existente, assim como sua tendência de transformação, possibilitando assim identificar os graus de impacto na gestão, nos programas e ações públicas ou até mesmo na alteração do clima urbano em função das transformações ocorridas na paisagem.

Portanto, a delimitação das áreas homogêneas de paisagem poderá não ser coincidente com o recorte administrativo ou com a área de planejamento, assim como não serão necessariamente coincidentes com os limites geográficos (ex.: bacia hidrográfica) ou administrativos (ex.: distrito).

Trata-se, portanto de um processo de análise proposto que não considera a paisagem 'como uma imagem', como 'uma visão ou como tudo aquilo que comporta o olhar', mas sim 'como uma estrutura morfológica, cujo entendimento demanda a divisão em unidades diversas'. O objetivo é a paisagem apreendida 'como uma totalidade em diferentes escalas de visualização'. O objetivo do trabalho é apresentar a aplicação do conceito de Unidade Morfo-territorial na escala metropolitana e intra-urbana. 


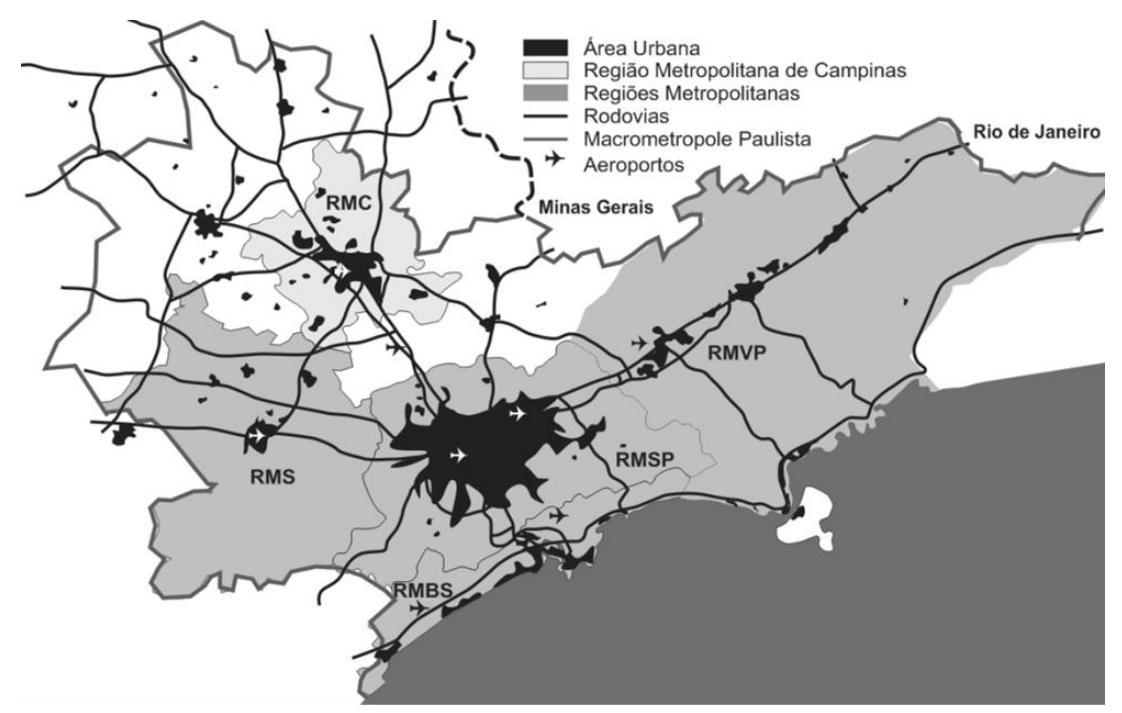

Figura 1. Inserção da Região Metropolitana de Campinas na Macrometrópole Paulista (fonte: autor sobre bases da Empresa Paulista de Planejamento Urbano, EMPLASA).

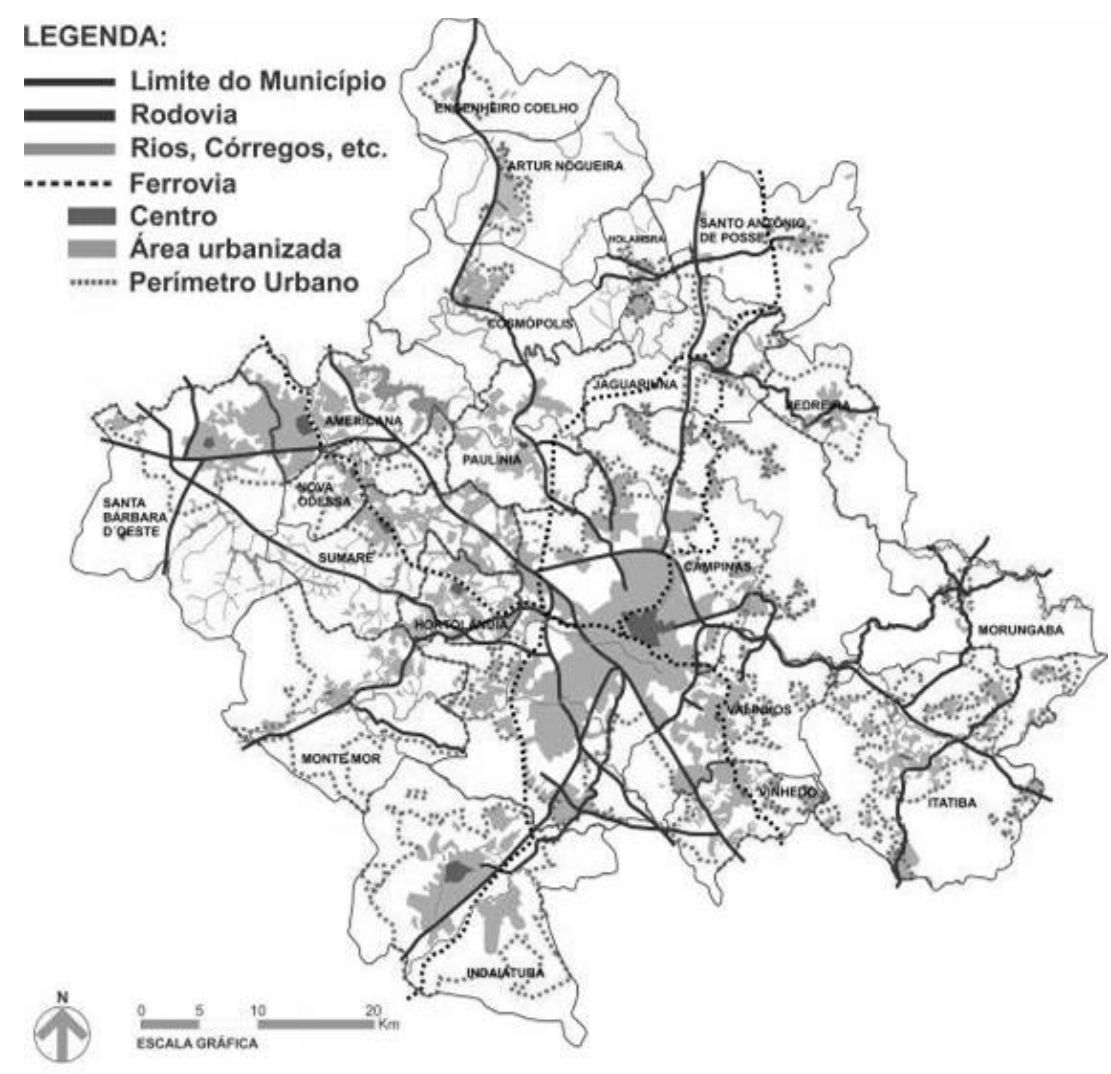

Figura 2. Base da Região Metropolitana de Campinas (fonte: autor sobre bases dos 20 municípios).

\section{Escala metropolitana}

Toma-se como recorte territorial a Região Metropolitana de Campinas (RMC). A região de estudo é uma das cinco regiões metropolitanas do estado de São Paulo (figuras 1 e 2) e se localiza em um eixo rodoviário que segue do Porto de Santos ao 


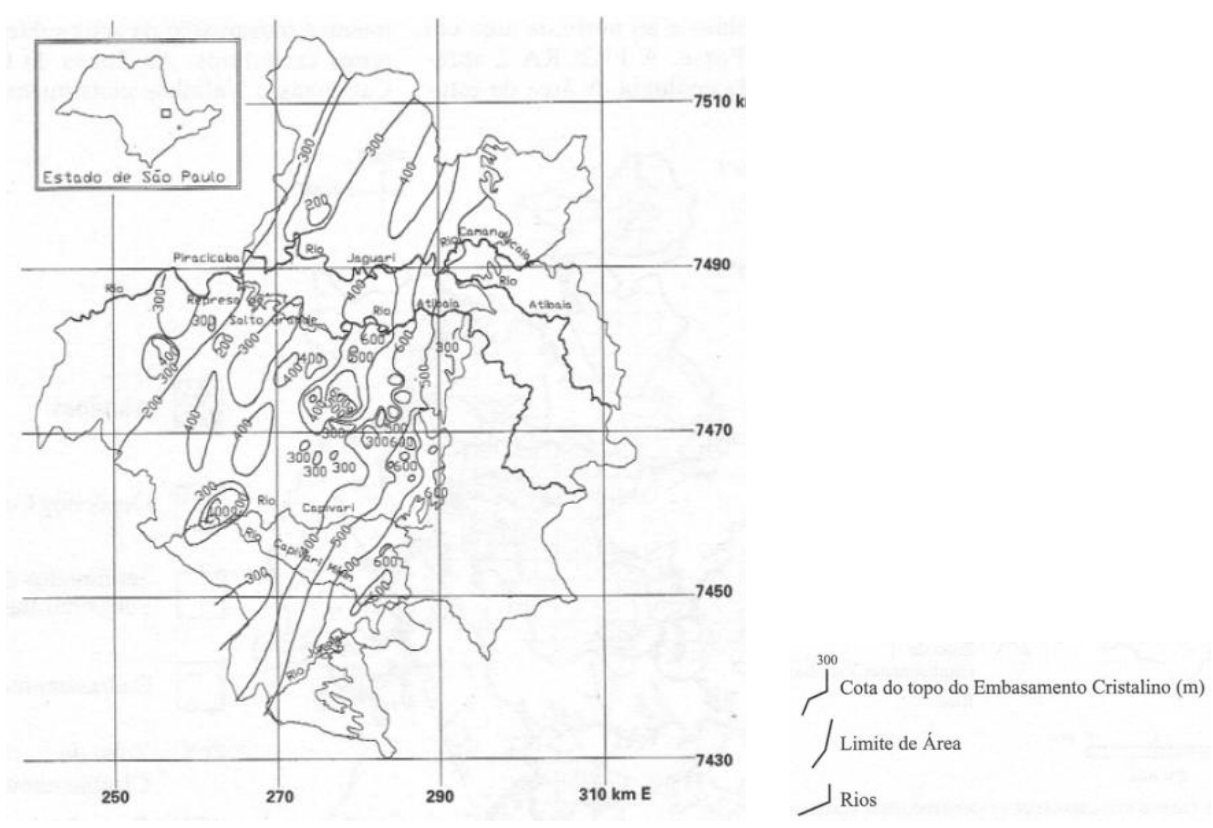

Figura 3. Suporte físico: topografia e sistema hídrico (fonte: modificado e adaptado de IG, 1993, e Yoshinaga e Silva, 1997).

interior do estado ligando as regiões metropolitanas da Baixada Santista, São Paulo, Campinas, Sorocaba e Vale do Paraiba. Trata-se da região que a Empresa Paulista de Planejamento Metropolitano (EMPLASA) convencionou chamar de 'Macrometrópole Paulista'. A população da 'Megalópole do Sudeste', região intitulada por Eugénio Queiroga em seus estudos, engloba a Macrometrópole Paulista e se estende até o Rio de Janeiro (Queiroga, 2002). Esta região superava 44 milhões de habitantes em 2010 tendo um Produto Interno Bruto (PIB) superior a 700 bilhões de dólares, isto é, concentra-se ali mais de um terço da economia brasileira. (IBGE, 2010).

Para delimitar Unidades Morfo-territoriais na Região Metropolitana de Campinas foram considerados os seguintes aspectos: i) suporte físico: topografia e sistema hídrico; ii) subsolo: tipo de solo e aquíferos; iii) valor do solo e tendências de transformação: pressão por urbanização, alteração de uso; iv) dinâmica da mobilidade sócio-espacial da região; e, por fim, v) forma do parcelamento urbano: contínuo ou descontínuo da mancha urbana; homogêneo ou heterogêneo.

As Unidades Morfo-territoriais extrapolam os limites do recorte territorial que se definiu à priori, no caso, a RMC. Portanto, não são necessariamente coincidentes com o recorte administrativo, assim como, não obedecem a limites geográficos.

Foram realizados levantamentos cartográficos em diferentes escalas e análise de imagens com informações específicas como: topografia, sistema hídrico, forma de parcelamento, mancha urbana, entre outros, sistematizando os dados levantados e contribuindo para a análise mais detalhada sobre a área investigada.

A seguir mostram-se algumas das bases desenvolvidas e pesquisadas. Estas bases foram consideradas e interpoladas na definição das Unidades Morfo-territoriais.

As figuras 3, 4 e 5 referem-se a aspectos físicos do solo e subsolo. Os aspectos como relevo e rede hídrica influenciam diretamente nas localizações das áreas urbanas. Outros aspectos, como tipos de solo e mapa de aquíferos servem para compreender as condições e áreas de percolação e recarga que necessitam de cuidado em sua ocupação e uso.

Nas figuras 6 e 7 lida-se com aspectos socioeconômicos ligados diretamente à política de solo urbano. Em estudos anteriores dos autores tem-se procurado considerar o mapa de valor de solo da região territorial estudada. Entretanto este dado não é algo facilmente obtido e normalmente 


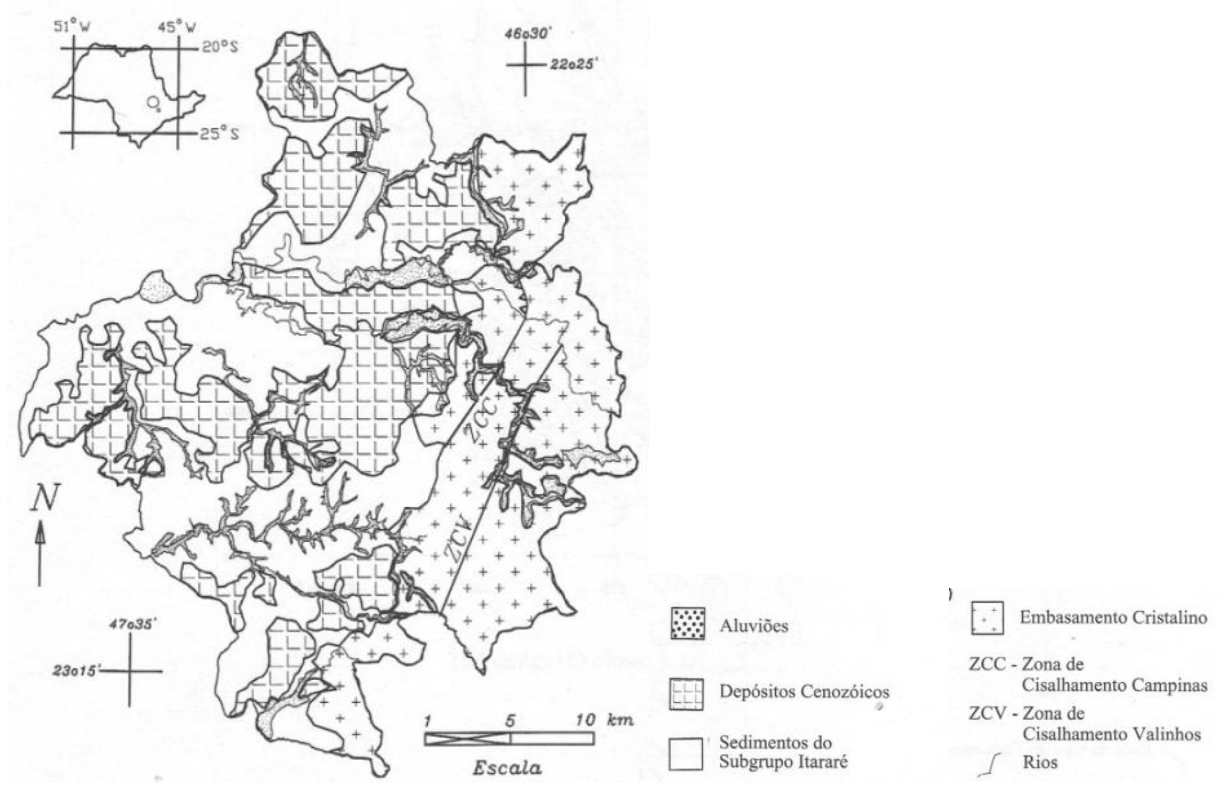

Figura 4. Delimitação de recortes em função do tipo de solo (fonte: IG, 1993, e Yoshinaga e Silva, 1997).
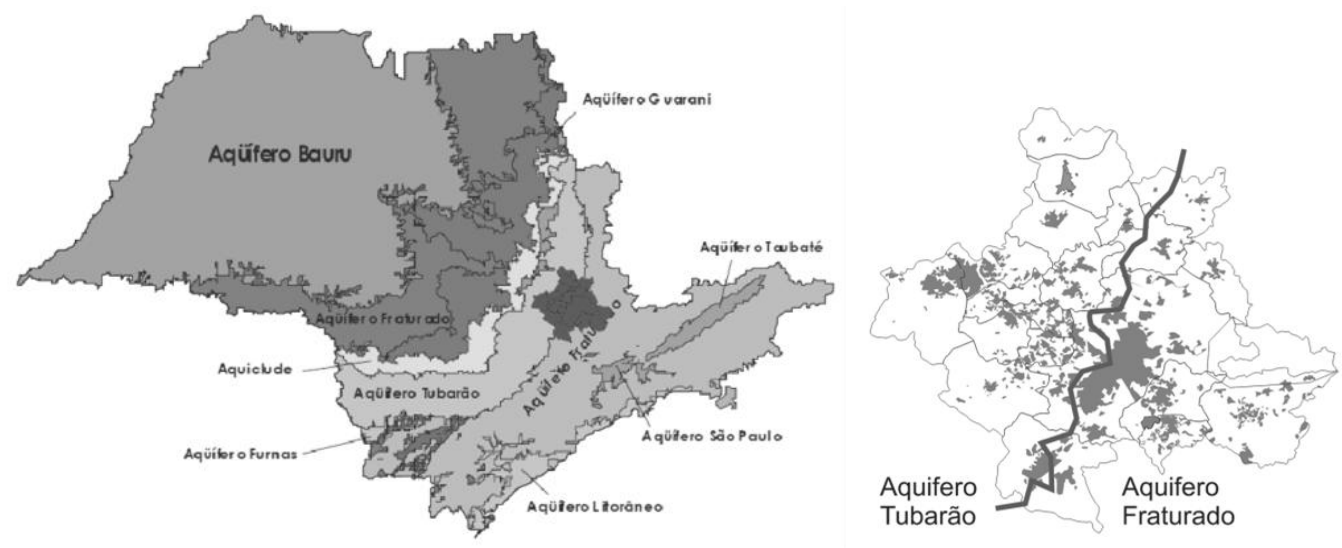

Figura 5. Sub-solo: aquíferos subterrâneos no estado de São Paulo. A região Metropolitana de Campinas esta delimitada em vermelho (fonte: mapa de águas subterrâneas do ESP 2005 - DAEE, IG, IPT, CPRM).

requer estudos específicos. Os dados, apresentados no presente estudo e que estão relacionados ao valor do solo urbano, foram objeto de levantamento e análise de pesquisas anteriores desenvolvidas pelo grupo de pesquisa dos autores entre 2011 e 2012 (Silva, 2013). O valor irá influenciar na mobilidade, assim como irá variar conforme a condição legal do solo. Ao analisar o mapa de valor de solo (Figura 6) em conjunto com o de mobilidade (Figura 7) identifica-se que os dois centros de maior destino também são os municípios que possuem o valor médio de solo mais elevado.
No Brasil, assim como em diversos países, a condição urbana ou rural do solo irá influir diretamente em seu valor. No Brasil é a 'lei de perímetro urbano' que delimita as áreas que são urbanas e, portanto podem ser parceladas, loteadas e dotadas de serviços urbanos.

Este perímetro pode ser contínuo ou descontínuo e é definido por lei municipal. $\mathrm{O}$ solo urbano (terra dentro do perímetro urbano) tem um valor maior que o solo rural ou não urbano. As terras não urbanizadas contidas dentro de perímetros urbanos têm, em geral, uma maior pressão para que se 


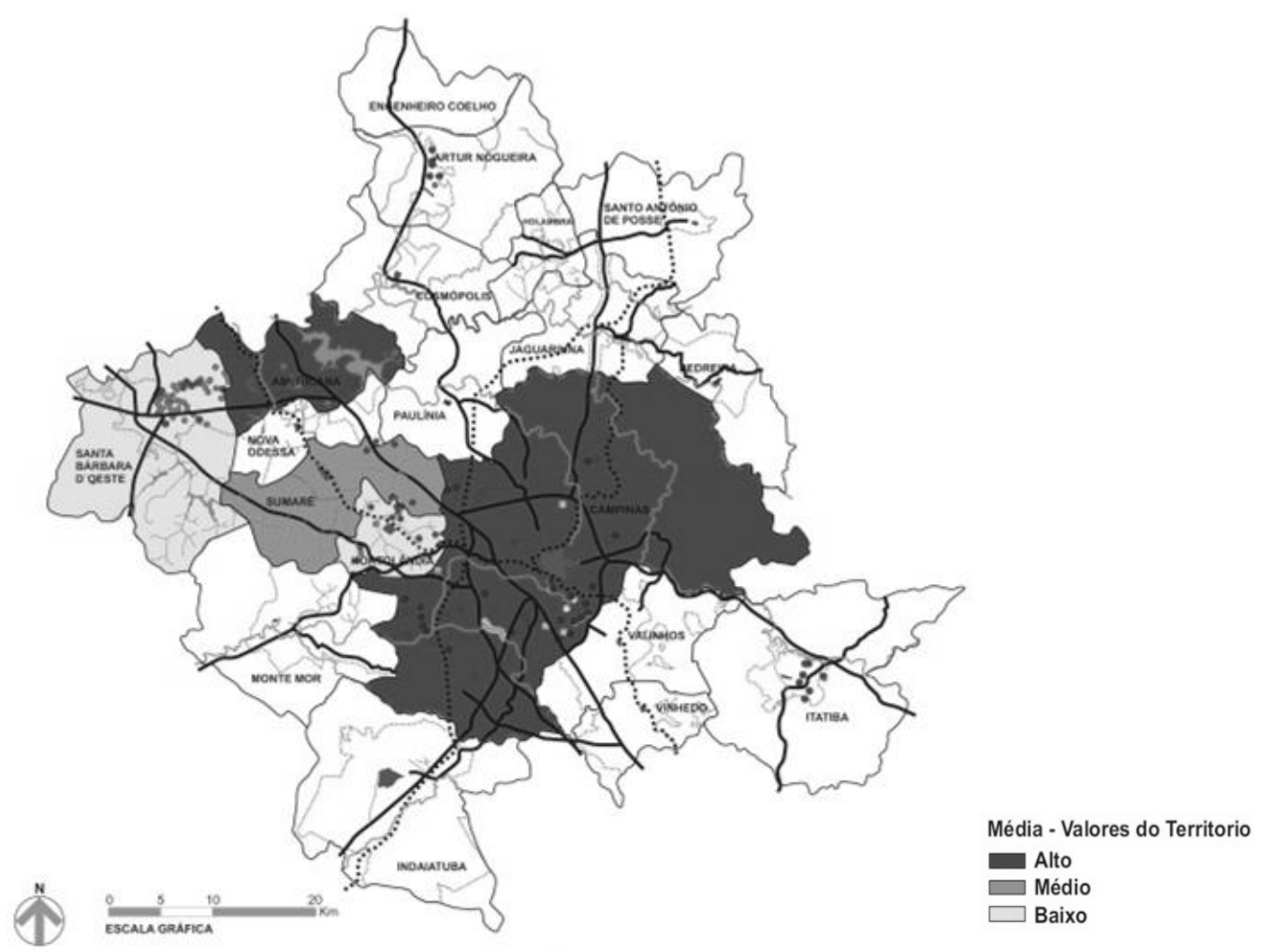

Figura 6. Valor médio do solo: mapeamento comparativo entre cinco municípios da RMU (fonte: Silva e Magalhães, 2013).

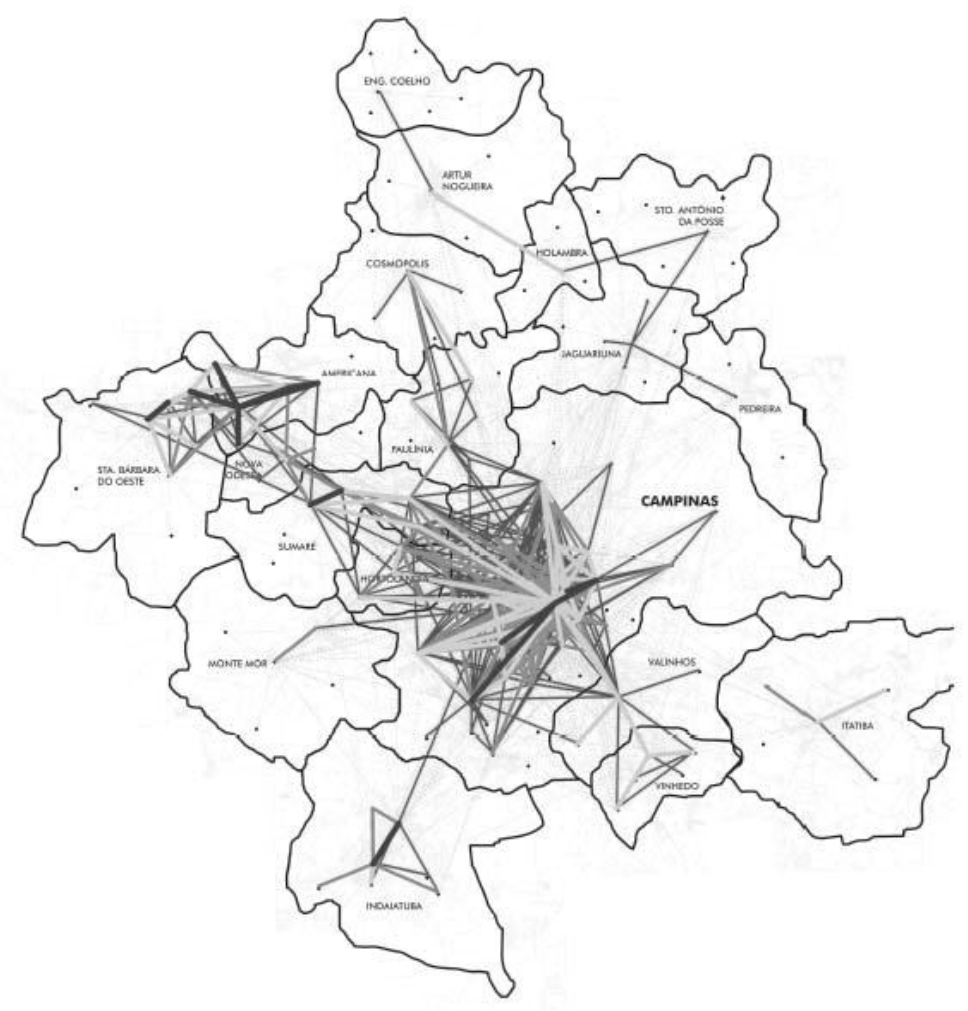

Figura 7. Dinâmica da mobilidade sócio-espacial da região: mapeamento de origem e destino na RMU. Observação: a diferenciação de tons de cinzento indica modalidade que não esta sendo levada em conta no presente estudo (fonte: PITU RMC 2015 - NESUR UNICAMP). 

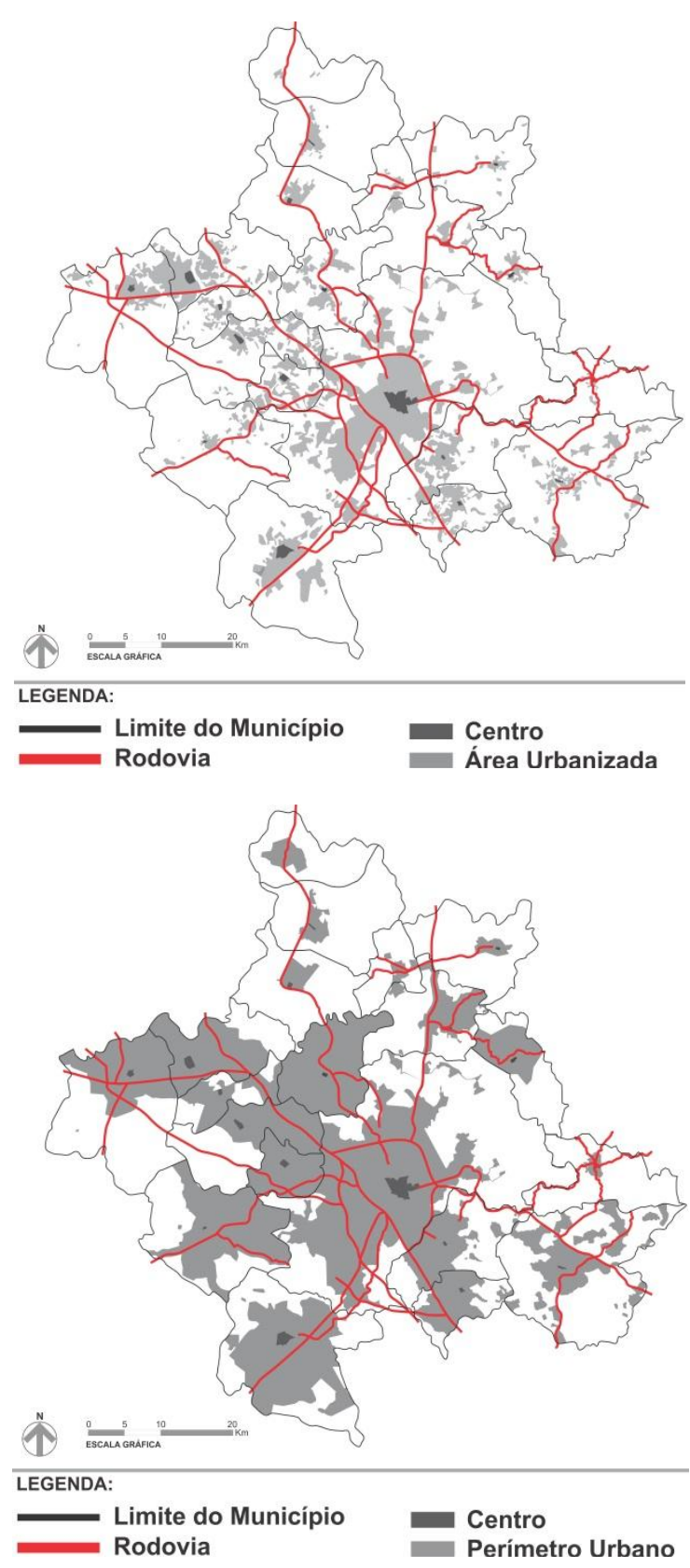

Figura 8. Tendências de transformação e forma do parcelamento urbano. Delimitação das áreas urbanizadas e do limite do perímetro urbano (fonte: Silva, 2013).

urbanizem. Cabe alertar, entretanto, que existem conflitos e contradições na definição de uma lei do perímetro urbano, justamente por interferir no valor do solo e nos interesses de uso de seus proprietários. A Figura 8 apresenta as áreas urbanizadas e as áreas contidas nos perímetros urbanos. Percebe-se que as áreas urbanas não são necessariamente áreas urbanizadas. A dispersão e fragmentação do território carregam, portanto a necessidade de diferentes escalas de análise para a compreensão do processo.
Delimitando as Unidades Morfo-territoriais da Região Metropolitana de Campinas

Considerando a dinâmica de mobilidade da RMC percebe-se uma grande influência das rodovias que a cruzam. As localizações de maior acesso e oferta de empregos também são aquelas com maior valor de solo urbano. É conveniente considerar, na delimitação de Unidades Morfo-territoriais (Figura 9), o eixo noroeste-sudeste, de grande mobilidade, e as demais conexões existentes com este eixo. 


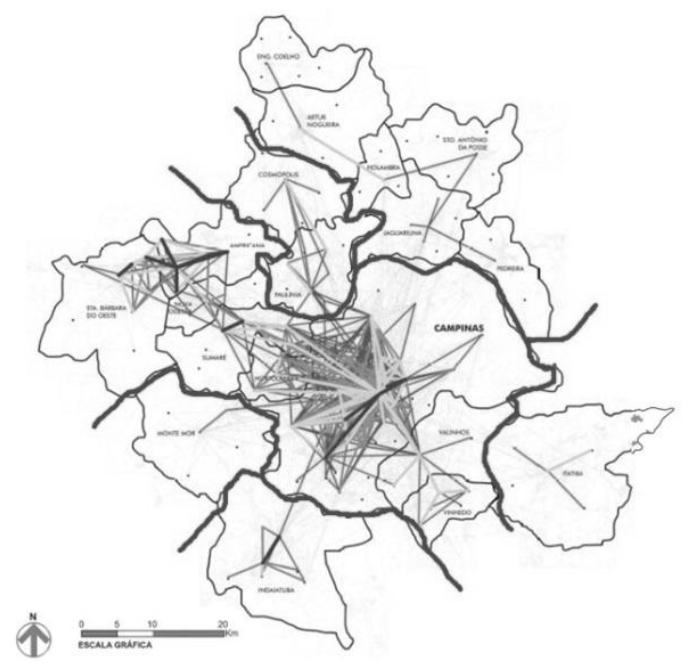

Figura 9. Delimitação, por meio das linhas a cheio, das Unidades Morfo-territoriais considerando a dinâmica da mobilidade sócioespacial da região (fonte: autor sobre PITU RMC 2015 - NESUR UNICAMP).

Desta forma estabelecem-se regiões onde a mobilidade guarda características semelhantes quanto à intensidade $\mathrm{e}$ direcionamento.

Ao sobrepor os limites desenhados sobre a dinâmica de mobilidade da RMC sobre as suas áreas consideradas pela lei de perímetro urbano como sendo urbanas, percebe-se a existência de áreas rurais circundadas por áreas urbanas, assim como áreas urbanas isoladas circundadas por áreas rurais. Considerou-se conveniente assinalar estas áreas assim como delimitar os limites entre o urbano e o rural (Figura 10).

Ao sobrepor os limites desenhados sobre os mapas que caracterizam os aspectos físicos da região percebe-se que o relevo se apresenta como um indutor do processo. As linhas desenhadas sobre os mapas que abrangiam os aspectos socioeconômicos (figuras 6, 7 e 8) dialogam com o suporte físico cabendo destacar algumas poucas subdivisões delimitadas na Figura 11 em magenta.

Os limites são agora sobrepostos sobre as áreas urbanizadas que indicam, após análise, características distintas de tecidos. Os limites são delimitados em laranja na Figura 12. A Figura 5 revela que a $\mathrm{RMC}$ está sobre dois distintos aquíferos: aquífero Tubarão a leste da linha azul (Figura 9) e aquífero Fraturado, a oeste. Considerou-se importante levar em conta os aquíferos por entendermos que as diretrizes de preservação ou transformação, fim último da presente análise, devem considerar a relevância do aquífero para a região. Portanto, considerando o limite existente entre aquíferos definiram-se hipóteses de 38 Unidades Morfo-territoriais (Figura 13).

Cada Unidade Morfo-territorial tem características, potencialidades e entraves distintos. Entretanto é razoável pensar-se que existem 'tipos' de Unidades Morfoterritoriais. Entende-se por tipo de Unidade Morfo-territorial as unidades que, na constituição da paisagem formada pela interação entre homem e suporte físico, guardam semelhanças quanto às suas características morfológicas. Entretanto cabe salientar que cada Unidade Morfo-territorial é sempre única.

Com o intuito de apresentar a análise das demais escalas - intraurbana e local - serão relatados os procedimentos utilizados para a leitura e análise da Unidade Morfo-territorial 5 delimitada na Figura 13. Na apresentação da escala intraurbana avança-se na discussão de como o procedimento de identificação dos tipos de Unidades Morfo-territoriais pode auxiliar na análise.

\section{Escala intraurbana}

O recorte territorial trabalhado localiza-se na Unidade Morfo-territorial 5 (UMT 5, Figura 13) em área consolidada da cidade de Campinas, núcleo da RMC. Este recorte é dotado de infraestrutura e está localizado na porção territorial com valor do solo mais elevado do município.

Enfatiza-se que o recorte físico geográfico se mostra conveniente às investigações pretendidas. A paisagem não se limita nem a um recorte administrativo, nem tão pouco, a um recorte físico-geográfico. A dinâmica do território, as características fundiárias e os aspectos de acessibilidade irão influir de forma marcante sobre o uso e ocupação do solo.

Desta forma pode-se observar que em uma porção da Unidade Morfo-territorial 5 (escala regional) é possível identificar 18 Unidades Morfo-territoriais na escala intraurbana, sendo que apenas três (UP3, UP9 e UP11) estão completamente inseridas no recorte da sub-bacia. Para a definição das 


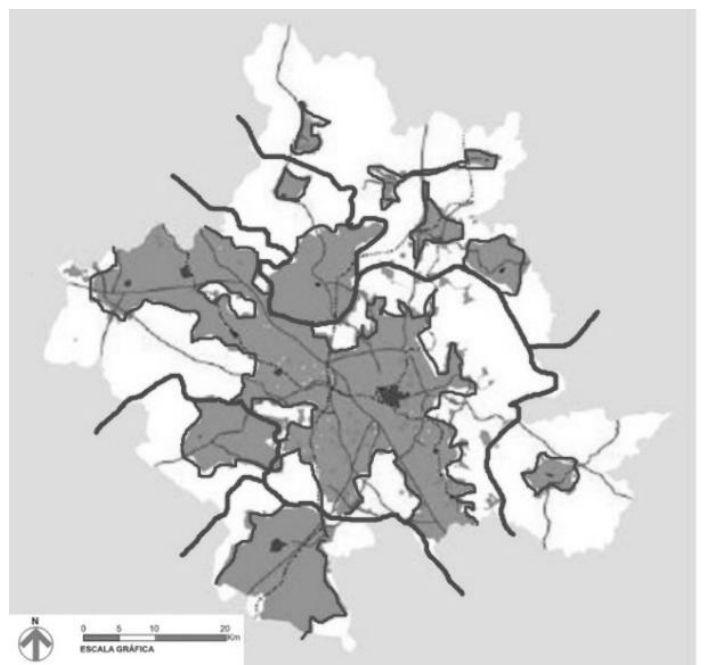

Figura 10. Delimitação, por meio das linhas a cheio, das Unidades Morfo-territoriais considerando a delimitação do limite do perímetro urbano (fonte: autores sobre Silva, 2013).

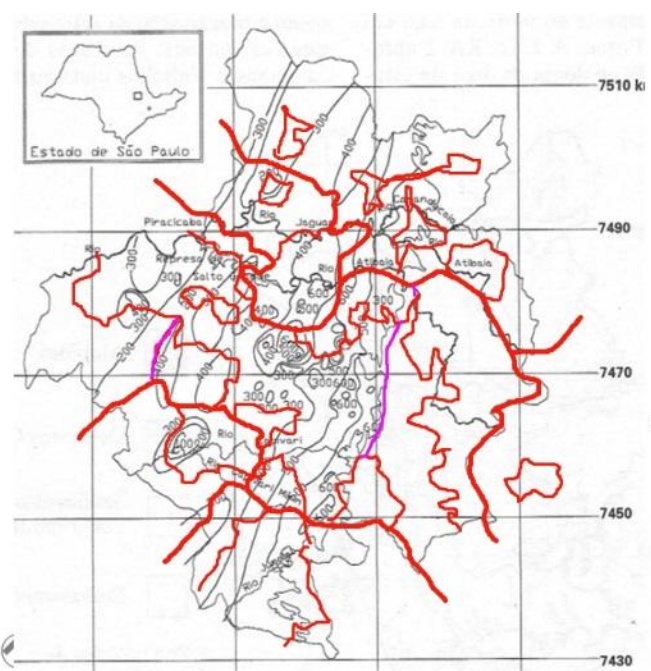

Figura 11. Sub-solo: tipo de solo. Delimitação, por meio das linhas violetas, de recortes das Unidades Morfo-territoriais delimitadas em vermelho, em função do tipo de solo (fonte: autores sobre IG, 1993).

Unidades Morfo-territoriais, nesta escala, foram utilizados os critérios definidos na Tabela 1.

O primeiro procedimento foi descrever as características de cada Unidade Morfoterritorial conforme Tabela 2.

Sintetizando, as 18 Unidades Morfoterritoriais identificadas que guardam características semelhantes entre si foram agrupadas em tipos morfológicos e

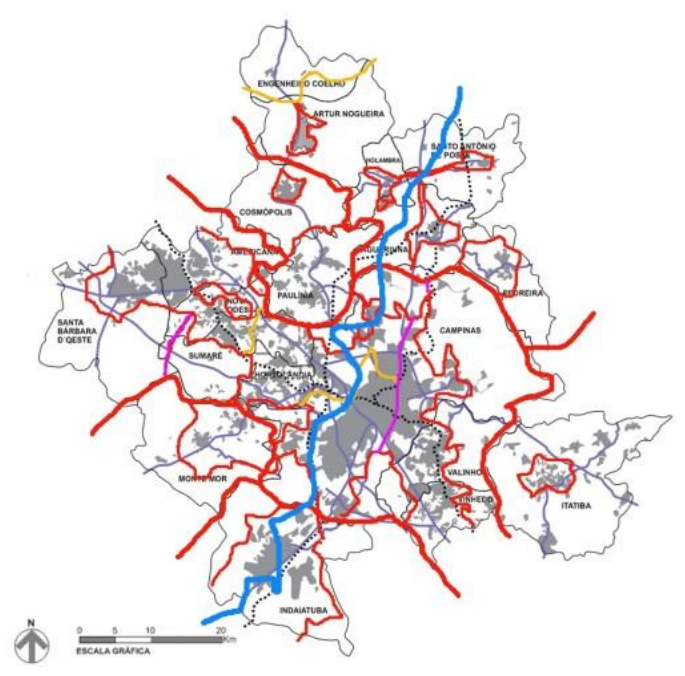

Figura 12. Delimitação, por meio das linhas vermelhas e violetas, das Unidades Morfoterritoriais considerando a rede hídrica superficial e as águas subterrâneas (fonte: autores sobre Silva, 2013).

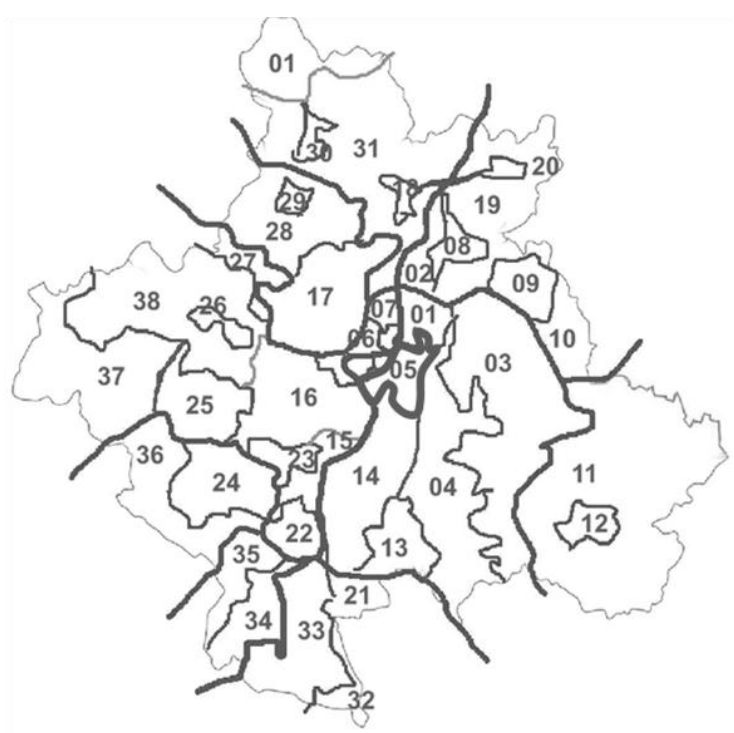

Figura 13. Delimitação das Unidades Morfoterritoriais com destaque da unidade 5 a ser analisada no presente artigo.

posteriormente organizadas em 'grupos' caracterizados pelos elementos morfológicos chave (Tabela 3 e Figura 4). Depois de proceder a uma longa análise busca-se uma síntese, representada pela Tabela 3 , onde se relaciona as Unidades Morfo-territoriais com o elemento morfológico indutor. Cabe destacar que os tipos E e F são os espaços livres de edificação que induzem a delimitação das unidades. 
Tabela 1. Critérios para definição das Unidades Morfo-territoriais

\begin{tabular}{|c|c|}
\hline Item & Sub-item \\
\hline $\begin{array}{l}\text { Forma do } \\
\text { parcelamento }\end{array}$ & $\begin{array}{l}\text { Constituição das vias } \\
\text { Dimensões de quadras } \\
\text { Quantidade e distribuição dos espaços de lazer } \\
\text { Presença de espaços institucionais } \\
\text { Presença de áreas de preservação e proteção ambiental }\end{array}$ \\
\hline $\begin{array}{l}\text { Tipos de usos e } \\
\text { ocupações }\end{array}$ & $\begin{array}{l}\text { Padrão edilício } \\
\text { Números de afastamentos e existência de recuos } \\
\text { Tamanho de lote }\end{array}$ \\
\hline $\begin{array}{l}\text { Tendências ou } \\
\text { constatações de } \\
\text { transformação }\end{array}$ & $\begin{array}{l}\text { Potencial edilício permitido pela legislação } \\
\text { Existência de processo de verticalização } \\
\text { Existência de processo de desmembramento ou remembramento } \\
\text { Presença de alteração de uso }\end{array}$ \\
\hline $\begin{array}{l}\text { Espaços livres de } \\
\text { edificação }\end{array}$ & $\begin{array}{l}\text { Padrão viário } \\
\text { Dimensões das calçadas } \\
\text { Tipos de cercamentos dos lotes } \\
\text { Dimensões e articulações das praças } \\
\text { Presença de parques urbanos }\end{array}$ \\
\hline
\end{tabular}
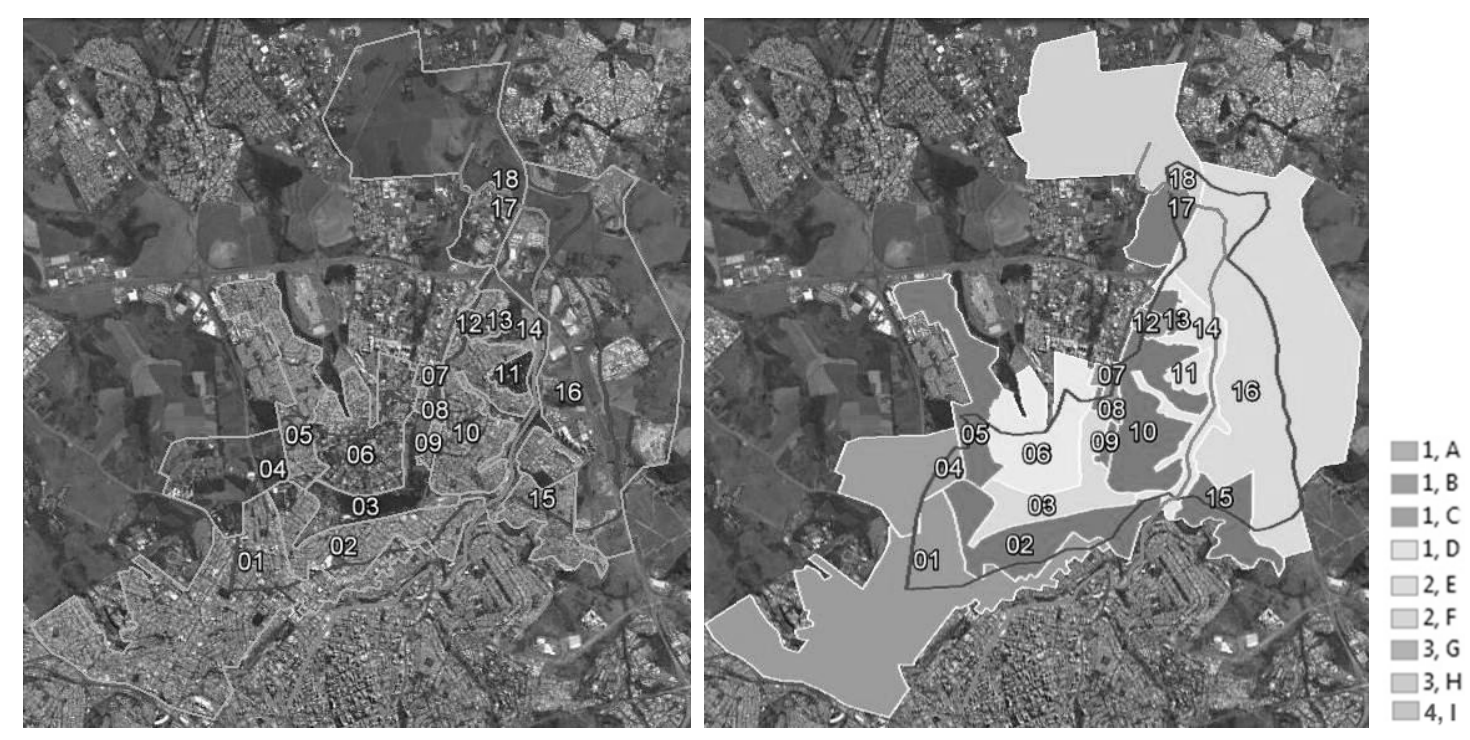

Figura 14. As Unidades Morfo-territoriais extrapolam o recorte territorial da bacia hidrográfica. Grupos indicados de 1 a 4 / Tipos indicados de A a (fonte: autores sobre Google Earth). 
Tabela 2. Caracterização das diferentes Unidades Morfo-territoriais - área de estudo

Unidade Características das Unidades Morfo-territoriais

Morfo-

territorial

UP01 Predominância de casarios horizontais com afastamento de um dos lados, onde ocorre um processo de verticalização. Interessante notar que a verticalização está predominantemente junto a linha de divisão de sub-bacia, portanto no terreno de cota mais alta.

UP02

Semelhança com a UP01 sem o referido processo de verticalização.

UP03 Caracteriza-se por ser livre de edificação abrangendo o Parque Taquaral e pelo entorno da Avenida do Café.

UP04 Prevalece a presença de espaços livres de urbanização com uso institucional e de pesquisa, onde estão localizadas o Instituto Agronômico de Campinas (IAC), o Instituto de Tecnologia de Alimentos (IAL) e a Coordenadoria de Assistência Técnica Integral (CATI), órgão da Secretaria de Agricultura e Abastecimento do Governo do Estado de São Paulo.

UP05 Predominância de casarios horizontais com afastamento de um dos lados semelhante a UP02.

UP06 Predominância de casarios horizontais com afastamento de três a quatro lados.

UP07 Conjunto de sete quadras com o tipo morfológico UP02.

UP08 Caracterizada por edificações soltas no grande lote semelhante a um campus. Ex.: área da Companhia Paulista de Força e Luz (CPFL). Unidade 3 da Faculdade Comunitária de Campinas da Rede Anhanguera Educacional. Esta unidade é cortada pela Rodovia Miguel Noel Nascimento Burnier que esta alteada em relação às vias locais lindeiras onde se desenvolve comércios em edificações horizontais com um ou dois afastamentos.

UP09 Tipo de unidade semelhante a UP07 composta por quatro quadras.

UP10 Assim como a UP02 tem predominância de casarios horizontais com afastamento de um dos lados. Entretanto o parcelamento, ao seguir o relevo existente, resulta em um desenho de quadras mais orgânico.

UP11 Casarios grandes, soltos no lote. A dimensão dos lotes e das edificações assim como a quantidade de vegetação arbórea caracterizam esta unidade.

UP12 Composta pela Cidade Judiciária e o DER de Campinas. Assemelha-se a UP08.

UP13 Tipo morfológico semelhante a UP10 inclusive traçado e quadras.

UP14 Caracteriza-se pela presença de espaços livres de edificação ou pela ocupação irregular destes espaços.

UP15 Tipo morfológico semelhante a UP02.

UP16 Caracteriza-se por glebas urbanizadas como condomínios fechados de forma descontinua. Os grandes empreendimentos caracterizam a unidade. Ex.: Sansung, Alphaville D. Pedro, Careffour, Residencial Bouganville, etc. A ETE Anhumas localiza-se nesta unidade.

UP17 Casarios horizontais com afastamentos de um ou dois lados em parcelamento não consolidado.

UP18 Caracteriza-se como glebas não urbanizadas. Área prevista para o Ciatec II (Campinas). 
Tabela 3. Caracterização das Unidades Morfo-territoriais: tipos morfológicos e grupos

\begin{tabular}{lll}
\hline Tipos & Unidades Morfo-territoriais & Caracteristicas comuns \\
\hline Grupo I & O lote é o elemento morfológico estruturador \\
\hline Tipo A & UP01 & Casarios horizontais em processo de verticalização \\
Tipo B & UP02 - UP05 - UP07 - UP09 - & Casarios horizontais \\
& UP10 - UP13 - UP15 & \\
Tipo C & UP17 & Casarios horizontais não consolidado \\
Tipo D & UP06 - UP11 & Casarios horizontais com afastamentos em 3 e 4 lados \\
\hline Grupo II & O espaço livre de edificação é o elemento morfológico estruturador \\
\hline Tipo E & UP03 & Espaço livre de edificação \\
Tipo F & UP14 & Ocupação de espaços livres de edificação \\
\hline Grupo III & O lote e a quadra não estão presentes como elementos morfológicos \\
\hline Tipo G & UP04 - UP08 - UP12 & Campus (edifício no meio de arborização intensa) \\
& UP16 & Glebas urbanizadas por grandes empreendimentos \\
Tipo H & Composto por Unidades Morfo-territoriais não urbanizadas \\
\hline Grupo IV & Glebas não urbanizadas \\
\hline Tipo I & UP18 & \\
\hline
\end{tabular}

\section{Escala local}

Passada a apresentação das duas escalas, regional e intraurbana, opta-se por apresentar a síntese desenvolvida referente aos tipos de quadra urbana presentes no recorte intraurbano estudado acima. O objetivo é demonstrar a necessidade de estabelecer uma relação entre as três escalas de análise. Grupos e tipos identificados se materializam com a aproximação da escala sendo as dimensões e tipo edilício elementos chaves da análise. Apresenta-se a seguir os resultados desta análise em uma tabela síntese, a Tabela 4.

$\mathrm{O}$ método de trabalho sugere uma aproximação das três escalas de maneira simultânea. Acredita-se que o conhecimento se constrói a partir das alternâncias entre as três escalas aqui apresentadas. Portanto a investigação ocorre nas três escalas de maneira simultânea e são sistematizadas separadamente para facilitar o processo de análise.

\section{Considerações finais}

$\mathrm{O}$ artigo tem a intenção de contribuir para o debate concetual e metodológico. Apresentar os conceitos e termos adotados assim como os procedimentos de análise utilizados. As Unidades Morfo-territoriais delimitadas em diferentes escalas auxiliam na identificação de características, potencialidades e entraves que por sua vez, possibilita gerir e intervir sobre o território de forma mais sistêmica e integrada.

A delimitação de áreas homogêneas de paisagem apresentada envolve tanto as dimensões físico-espaciais, como as dinâmicas sócio-econômicas. O método possibilita incorporar qualquer aspecto sócioeconômico que seja possível de se espacializar sobre o território. Cabe observar que o presente estudo iniciou-se pela análise das características relacionadas ao valor de solo, mobilidade e caracterização jurídica do solo (urbano ou rural, etc.). Portanto não se parte somente do entendimento físicoespacial, mas também dos aspectos socioeconômicos que induzem sua transformação.

Os resultados obtidos apontam para uma compreensão multiescalar necessária para um avanço no entendimento do fenômeno da dispersão urbana, que no Brasil tem características específicas apesar de ser observada em outras regiões do globo em função da tecnologia de mobilidade instaurada sob o território. Tomou-se como fundamento teórico o conhecimento produzido pelos estudos da morfologia urbana, sobre paisagem urbana e políticas de solo urbano, buscando contribuir para o entendimento e delimitação dos campos científicos da arquitetura e urbanismo, que no caso brasileiro, são integrados na mesma graduação e área de pesquisa. 


\section{Tabela 4. Síntese}

\begin{tabular}{|c|c|c|}
\hline $\begin{array}{l}\text { Grupo } \\
\text { e Tipo }\end{array}$ & Recorte & Unidade Morfo-territorial \\
\hline $\begin{array}{l}\text { U.P. } \\
\text { Grupo I } \\
\text { Tipo A }\end{array}$ & & $\begin{array}{l}\text { Casarios horizontais e edifícios verticais. Quadra padrão (menor } \\
\text { que } 100 \mathrm{~m} \text { ). Lotes médios. Pouco espaço livre intraquadra. } \\
\text { Processo de verticalização em curso. }\end{array}$ \\
\hline $\begin{array}{l}\text { U.P. } \\
\text { Grupo I } \\
\text { Tipo B }\end{array}$ & & $\begin{array}{l}\text { Casarios horizontais. Quadra padrão (menor que } 100 \mathrm{~m} \text { ). Lotes } \\
\text { pequenos. Pouco espaço livre intraquadra. Processo de ocupação } \\
\text { consolidado. }\end{array}$ \\
\hline $\begin{array}{l}\text { U.P. } \\
\text { Grupo I } \\
\text { Tipo C }\end{array}$ & & $\begin{array}{l}\text { Casarios horizontais e galpões. Quadra fora de padrão (entre } 200 \\
\text { e } 400 \text { m). Lotes pequenos e médios. Algum espaço livre } \\
\text { intraquadra. Processo de ocupação em consolidação. }\end{array}$ \\
\hline $\begin{array}{l}\text { U.P. } \\
\text { Grupo I } \\
\text { Tipo D }\end{array}$ & & $\begin{array}{l}\text { Casarios horizontais com afastamentos em } 3 \text { e } 4 \text { lados. Quadras } \\
\text { grandes (entre } 200 \mathrm{~m} \text { ). Lotes médios. Algum espaço livre } \\
\text { intraquadra. Processo de ocupação consolidado. }\end{array}$ \\
\hline $\begin{array}{l}\text { U.P. } \\
\text { Grupo II } \\
\text { Tipo E }\end{array}$ & & $\begin{array}{l}\text { Espaço livre de edificação. Quadras fora de padrão (acima de } 400 \\
\text { m). Espaço livre público. }\end{array}$ \\
\hline $\begin{array}{l}\text { U.P. } \\
\text { Grupo II } \\
\text { Tipo F }\end{array}$ & & $\begin{array}{l}\text { Ocupação de espaços livres de edificação. Quadras grandes } \\
\text { (aproximadamente } 200 \text { m). Lotes irregulares e pequenos. Pouco } \\
\text { espaço livre intraquadra. Processo de ocupação consolidado. }\end{array}$ \\
\hline $\begin{array}{l}\text { U.P. } \\
\text { Grupo III } \\
\text { Tipo G }\end{array}$ & & $\begin{array}{l}\text { Edifício no meio de espaço livre. Quadras grandes (acima de } 200 \\
\text { m). Lotes irregulares, grandes e médios. Processo de ocupação } \\
\text { em consolidação. }\end{array}$ \\
\hline $\begin{array}{l}\text { U.P. } \\
\text { Grupo III } \\
\text { Tipo H }\end{array}$ & & $\begin{array}{l}\text { Glebas urbanizadas por grandes empreendimentos. Quadras } \\
\text { grandes (acima de } 200 \mathrm{~m} \text { ). Lotes médios. Processo de ocupação } \\
\text { em consolidação. }\end{array}$ \\
\hline $\begin{array}{l}\text { U.P. } \\
\text { Grupo IV } \\
\text { Tipo I }\end{array}$ & & Glebas não urbanizadas. Inexistência de quadras e lotes. \\
\hline
\end{tabular}




\section{Nota}

Uma versão prévia deste artigo foi apresentada no 21st International Seminar on Urban Form realizado no Porto entre 3 e 6 de Julho de 2014.

\section{Referências}

Bakhtin, M. (1976) 'Discurso na vida e discurso na arte: sobre a poética sociológica'. em Voloshinov, V. N. (ed.) Freudism - a marxist critique (Academic Press, Nova Iorque).

Bakhtin, M. (1997) Marxismo e filosofia da linguagem (Hucitec, São Paulo).

Conzen, M. R. G. (1988) 'Morphogenesis, morphological regions and secular human agency in the historic townscape, as exemplified by Ludlow' em Denecke, D. e Shaw, G. (eds.) Urban historical geography: recent progress in Britain and Germany (Cambridge University Press, Cambridge), 252-72.

Costa, S. A. P. (2007) 'O estudo da forma urbana no Brasil', Arquitextos (http://www.vitruvius. com.br/revistas/read/arquitextos/08.087/220) consultado em 10 de Janeiro de 2013.

Freire, O. (ed.) (2002) Projeto Orla: fundamentos para gestão integrada (MMA/MPOG, Brasília).

Lamas, J. M. R. G. (1993) Morfologia urbana e desenho da cidade (Dinalivro, Lisboa).

Macedo, S. S. (1997) 'Paisagem, lotes e tecidos urbanos', Paisagem e Ambiente 10, 13.

Metzger, J. P. (2001) 'O que é ecologia da paisagem?', Biota Neotropica 1, 1-9.

Pezzuto, C. C. (2007) 'Avaliação do ambiente térmico nos espaços urbanos abertos: estudo de caso em Campinas, SP', Tese de Doutoramento não publicada, Universidade Estadual de Campinas, Brasil.

Queiroga, E. (2002) 'A megalópole e a praça: o espaço entre a razão de dominação e a razão comunicativa', Tese de Doutoramento não publicada, Universidade de São Paulo, Brasil.

Reis, N. G. (2006) Notas sobre urbanização dispersa e novas formas de tecido urbano (Via das Artes, São Paulo).

Santos, M. (2002) O país distorcido (Publifolha, São Paulo).

Silva, J. M. P. (2013) Os papéis dos investimentos públicos (PUC, Campinas).

Silva, J. M. P. e Magalhães, N. C. T. (2013) 'Contradições da Região Metropolitana de Campinas. Delimitação das ZEIS e a localização dos investimentos públicos em habitação de interesse social', Arquitextos (http://www.vitruvius.com.br/revistas/read/arqui textos/14.158/4821) consultado em 14 de Abril de 2014.

Tricart, J. J. L. (1979) 'Paysage et écologie. Revue de Géomorphologie dynarnique: géodynamique externe', Etudes intégrée $d u$ milieu naturel 25, 81-95.

Whitehand, J. W. R. (2001) 'British urban morphology: the Conzenian tradition', Urban Morphology 5, 103-9.

Whitehand, J. W. R. (2007) 'Conzenian urban morphology and urban landscapes' em Proceedings of the $6^{\text {th }}$ International Space Syntax Symposium (Istanbul Technical University, Istambul).

Yoshinaga-Pereira, S. e Silva, A. A. K. (1997) Condições de ocorrência das águas subterrâneas e do potencial produtivo dos sistemas aquíferos na região metropolitana de Campinas - SP', Revista do Instituto Geológico 18, 23-40.

\title{
Tradução do título, resumo e palavras-chave
}

Application of the concept of Morpho-territorial Unit in the metropolitan, intraurban and local scales

\begin{abstract}
The urban forms in the Metropolitan Region of Campinas, resulting from urban fragmentation and dispersion, need further investigation. This paper aims at presenting a method of analysis that relates different bodies of knowledge: landscape, ecology and morphological studies. The concepts, methods and techniques presented here are the result of years of discussion within the QUAPA-SEL (Quadro de Paisagismo - Sistema de Espaços Livres) research network that studies the relationship between the system of open spaces and the built form. The paper presents the analytical procedures in three different scales: i) metropolitan area, consisting of 20 cities; ii) neighborhoods, formed by different urban tissues, and iii) urban block, where both open spaces and built forms create the urban space. In the three scales, the system of open spaces has the main role. The results show that the method of analysis offers valuable insights on understanding of the phenomenon of urban dispersion and fragmentation. The method aims at gathering different analytical techniques from different bodies of knowledge, integrating morphological procedures and techniques used within ecology and urban landscape studies.
\end{abstract}

Keywords: urban morphology, urban form, landscape, ecology 